\title{
LA RETRIBUCIÓN DE LOS MIEMBROS DEL CONSEJO RECTOR O DE LOS ADMINISTRADORES EN LAS SOCIEDADES COOPERATIVAS
}

\author{
POR \\ Belén GARCÍA ÁLVAREZ
}

\section{RESUMEN}

La remuneración de los miembros del Consejo Rector o de los administradores es un aspecto importante del gobierno corporativo de toda sociedad. En prácticamente todas las regulaciones se reconoce el derecho de los administradores de una sociedad cooperativa a ser resarcidos de los gastos que les origina el ejercicio de sus cargos. No sucede lo mismo con la posibilidad de que puedan ser retribuidos por el ejercicio de su cargo. Se presume generalmente que el cargo es gratuito, aunque en algunas regulaciones y supuestos ni siquiera se permite que tenga carácter retribuido. En cualquier caso, si se prevé estatutariamente que los administradores sean remunerados por el ejercicio de sus funciones, deberá analizarse su determinación, así como posibles límites en su fijación. En estrecha conexión con la remuneración de los administradores, se encuentra la posible impugnación de los acuerdos relativos a este aspecto del gobierno de las cooperativas. Por último, cabe discutir la incidencia que puede tener el hecho de que el cargo de administrador sea retribuido en cuanto a la responsabilidad de los administradores.

Palabras clave: sociedades cooperativas; administradores; retribución; gastos; responsabilidad.

Claves Econlit: P13, K12, K20, K22.

\footnotetext{
${ }^{1}$ Profesora de Derecho mercantil. Universidad de Deusto. Dirección de correo electrónico: belen.garcia@ deusto.es

REVESCO No 119 - Tercer Cuatrimestre 2015 - ISSN: 1885-8031 - www.ucm.es/info/revesco

http://dx.doi.org/10.5209/rev_REVE.2015.n119.49065

Fecha de recepción: 16/01/2015

Fecha de aceptación: 24/02/2015
} 


\title{
REMUNERATION OF MEMBERS OF THE GOVERNING BOARD OR MANAGERS IN COOPERATIVES
}

\begin{abstract}
The remuneration of the members of the Governing Board or managers is an important aspect of corporate governance in any type of society. In all regulations the right of managers of a cooperative society to be compensated for the expenses they incurred in the performance of their duties is recognized. Not so with the possibility that they may be paid by the exercise of his tasks. It is generally assumed that the position is unpaid, and in some regulations and in some cases not even allowed to take paid character. In any case, if managers are expected to be paid by the exercise of their functions, their determination should be analyzed and possible limits on its setting. In close connection with the remuneration of the managers, is the possible challenge of the corporate resolutions relating to remuneration of managers. Finally, we discuss the impact that the managers are rewarded in demanding liability to managers.
\end{abstract}

Keywords: cooperative society; directors; remuneration; expenses; liability.

\section{INTRODUCCIÓN*}

Un aspecto relevante, pero que no ha recibido tradicionalmente una atención particular en el ámbito de las sociedades cooperativas, es la remuneración de los miembros del Consejo Rector, o en su caso, del administrador único o administradores mancomunados o solidarios de la sociedad cooperativa. Ante el conflicto de intereses que se produce entre los administradores, cuyo interés personal, aun siendo, a su vez, socios, recae en especial sobre su retribución, y la sociedad cooperativa, debe diseñarse una política retributiva que logre la alineación de los intereses de ambas partes en beneficio común. Pues bien, ésta es una cuestión importante en aras de lograr un buen gobierno de las sociedades cooperativas (Muñoz; Briones, 2011: 175-177), aún más importante si cabe en el contexto económico actual.

\footnotetext{
* Una primera versión de este trabajo se presentó en el XV Congreso de investigadores en economía social celebrado los días 25 y 26 de septiembre de 2014 en Santander. Además, el presente trabajo se enmarca en el proyecto de investigación "Las obligaciones de transparencia y lealtad de los administradores en las sociedades de capital y en las entidades no lucrativas: Un enfoque uniformizador" (Ref. DER2012-35506), financiado por el Ministerio de Economía y Competitividad. Igualmente, en el Equipo de investigación "Poder público y empresa en un contexto multinivel y transnacional" (IT IT607-13).
} 
En este sentido, la legislación prevé que a los administradores de una sociedad cooperativa se les resarza de los gastos ocasionados por el desempeño de sus cargos, pero en cuanto a una retribución propiamente dicha no hay una posición uniforme en nuestro ordenamiento jurídico. En general se establece una presunción de gratuidad del cargo de administrador, y si se prevé su carácter retribuido se establecen una serie de restricciones.

Esta disparidad legislativa parece encontrar su fundamento último en la falta propiamente de ánimo de lucro de la sociedad cooperativa, así como en el hecho de que la finalidad de la cooperativa sea satisfacer las necesidades de sus socios mediante el desarrollo de la actividad cooperativizada. Hay que señalar que un régimen muy similar tienen los miembros del Consejo de vigilancia, Intervención u otras denominaciones que recibe el órgano de supervisión en función de la regulación aplicable a la sociedad cooperativa.

En este trabajo, se examinará en primer lugar el derecho del administrador al resarcimiento de los gastos ocasionados por el desempeño del cargo, ya que esta puede ser una vía en ocasiones para obtener una retribución encubierta por parte de los administradores. A continuación, se abordará el derecho o no que puede tener el administrador a ser retribuido por el ejercicio de sus funciones, y en caso afirmativo bajo qué condiciones se puede fijar su importe. Una vez examinado el régimen aplicable a la retribución de los administradores, se hará referencia a la posible impugnación de los acuerdos sociales que versen sobre la remuneración de los administradores. Igualmente, se atenderá a la incidencia que puede tener el carácter retribuido o no del cargo en la exigencia de responsabilidad a los administradores, así como las eventuales consecuencias derivadas de la percepción de una remuneración excesiva o desproporcionada. Finalmente, se expondrán unas conclusiones sobre la remuneración de los administradores en una sociedad cooperativa y su incidencia en la mejora de su buen gobierno.

\section{DERECHO AL RESARCIMIENTO DE LOS GASTOS OCASIONADOS}

El hecho de que, como se comprobará más adelante, se presuma en general que el cargo de administrador en una sociedad cooperativa es gratuito, no implica que no se deba resarcir a éste por los gastos en los que pueda incurrir en el ejercicio de su cargo. En efecto, en prácticamente todas las regulaciones se establece el derecho del administrador de una sociedad cooperativa a ser resarcido de los gastos que le ocasiona el desempeño de su cargo [art. 40 in fine Ley 27/1999, de 16 de julio, de Cooperativas (en adelante LC); art. 43. párr. $2^{\circ}$ Ley 4/1993, de 24 de junio, de Cooperativas del País Vasco (en adelante LCE); art. 46.5. in 
fine Ley 8/2003, de 24 de marzo, de Cooperativas de la Comunidad Valenciana (en adelante LCCV); art. 47 de la Ley 5/1998, de 18 de diciembre, de Cooperativas de Galicia (en adelante, LCG); art. 62 in fine Ley 1/2003, de 20 marzo, de Cooperativas de Illes Balears (en adelante LCIB); art. 39.2. in fine Decreto Legislativo núm. 2/2014, de 29 de agosto, por el que se aprueba el texto refundido de la Ley de Cooperativas de Aragón (en adelante LCA); art. 38.6. in fine Ley 2/1998, de 26 marzo, de Sociedades Cooperativas de Extremadura (en adelante LSCExt); art. 53.párr. $2^{\circ}$ Ley 6/2013, de 6 noviembre, de Cooperativas de Cantabria (en adelante LCCan); art. 50.párr.2 Ley 4/2002, de 11 abril, de Cooperativas de Castilla y León (en adelante LCCyL); art. 43.5. in fine Ley 4/1999, de 30 de marzo, de Cooperativas de Madrid (en adelante LCM); art. 60.2. Ley 11/2010, de 4 de noviembre, de Cooperativas de Castilla-La Mancha (en adelante LCCyM); art. 49.párr.2 Ley 14/2011, de 23 diciembre, de Sociedades Cooperativas Andaluzas (en adelante LSCA); art. 76 in fine Ley 4/2010, de 29 junio, de Cooperativas del Principado de Asturias (en adelante LCPA); art. 51.párr.2 $2^{\circ}$ Ley 4/2001, de 2 julio, de Cooperativas de La Rioja (en adelante LCLR); art. 58 in fine Ley 8/2006, de 16 noviembre, de Sociedades Cooperativas de Región de Murcia (en adelante LSCRM)].

Se trata, en principio, de que el administrador no pierda dinero o no tenga que ponerlo de su bolsillo (García Más, 2001:190). Estos gastos se refieren, sobre todo, a gastos de dietas y desplazamientos a los lugares de reunión por parte de los miembros del Consejo Rector, así como otros posibles desplazamientos que deban hacer en el ejercicio de sus funciones o de trámites que deban hacer y que tengan algún coste particular.

En este sentido, se plantean problemas con las dietas, en especial, por la mera asistencia a las reuniones del órgano de administración. Se reconoce que este tipo de compensaciones suponen en realidad retribuciones en especie (Gadea, Sacristán, Vargas, 2009:310). En consecuencia, no se está resarciendo ningún gasto en el que haya podido incurrir el administrador, sino que en realidad se está compensando o pagando por el tiempo que el administrador ha "perdido" o ha usado para asistir a la reunión y ejercer una de las funciones propias de su cargo. Por tanto, constituye una forma de retribución encubierta del administrador, cuya licitud puede ser más discutible en función del contexto fáctico que la rodee, especialmente si el órgano de administración se reúne demasiadas veces al año teniendo en cuenta el tamaño y volumen económico de la cooperativa, el funcionamiento del órgano de administración (en particular si hay comisiones ejecutivas o consejero delegado) o 
los asuntos incluidos en el orden del día de las reuniones. Por estas razones, se discute su admisibilidad, no estando prevista la retribución del administrador. Algunos autores no lo admiten (Paniagua, 2005: 223), y otros, en cambio, consideran que estas dietas no constituyen retribución (Vicent Chuliá, 1990:745-746). Aunque hubiese una previsión estatutaria que estableciese que el cargo del administrador fuese retribuido, es igualmente discutible que se pueda infringir la reserva estatutaria y/o la reserva de la Asamblea General mediante la fijación de retribuciones encubiertas a través de la figura del resarcimiento de los gastos ocasionados por el desempeño del cargo de administrador.

Cabe señalar que en el art. 47 LCG se excluye expresamente como uno de los gastos a resarcir la asistencia a las reuniones de la Asamblea general por parte de los administradores de la sociedad cooperativa, guardando silencio al respecto el resto de la normativa aplicable a las cooperativas. La Jurisprudencia ha considerado lícita la percepción de este tipo de dietas por los administradores de una sociedad cooperativa. Así en la Sentencia del Tribunal Supremo de 18 de febrero de 1992, (Sala de lo Contencioso-Administrativo, Sección 2 2a) n ${ }^{\text {o }}$ 1599/1989 (RJ 1992, 2292) se afirma que la gratuidad del cargo no es incompatible con la percepción de compensación discontinuas por asistir a las reuniones del Consejo Rector, así como en la Sentencia de la Audiencia Provincial de Ciudad Real (Sección 2a), de 18 de abril de 2001, nº 85/2001 (JUR 2001, 233818). No obstante, en la Sentencia del Tribunal Supremo de 29 de septiembre de 2006, $\mathrm{n}^{\circ}$ 912/2006 (RJ 2006, 6499) se estima que las dietas por asistencia a reuniones no pueden entenderse incluidas en sentido estricto dentro del concepto de resarcimiento de los gastos ocasionados por el desempeño del cargo, pero a pesar de esta afirmación no declara responsables a los administradores debido a que no se acreditó la existencia de un daño, y a la aprobación de dichos gastos por parte de la Asamblea general con el consiguiente conocimiento por parte de los socios de la sociedad cooperativa de estas dietas. Igualmente, en la Sentencia del Tribunal Supremo de 11 de julio de 2007 no 809/2007 (RJ 2007/3883), se afirma que si el importe de las dietas por este concepto es abusivo, ya que su importe y la frecuencia de las reuniones no tienen una justificación razonable, se podría alegar abuso de derecho. En definitiva, se permiten indebidamente, salvo en la LCG, este tipo de dietas y su inclusión como gastos, y no como verdaderas retribuciones del administrador.

Igualmente, resulta controvertida la inclusión como gastos de las primas de seguros de responsabilidad civil de los administradores por el ejercicio de sus cargos, ya que también se pueden considerar una retribución en especie. La mayor parte de la doctrina estima que se 
trata de una retribución en especie (Pastor 2006:517; Roncero 2002:103-120), por lo que la sociedad cooperativa no podría abonar esta cantidad bien directamente, bien indirectamente resarciendo al administrador de dicho gasto. Otros consideran que esta afirmación no es acorde con el interés social de la contratación de este tipo de seguros y con la totalidad de los casos (Gadea, Sacristán, Vargas, 2009:311; Iribarren 2005:100), y que, sobre todo, esto se hace más patente cuando el cargo de administrador no es retribuido (Gadea, Sacristán, Vargas, 2009:311). Por tanto, algunos autores estiman que si las primas las paga la sociedad es un gasto más de gestión, y si lo hace el administrador, es un gasto inherente a su cargo (Gadea, Sacristán, Vargas, 2009:311). Realmente esta cuestión no debería ser tratada de forma diferente en función del carácter retribuido o no del cargo de administrador, puesto que la diligencia en el ejercicio de su cargo debe ser igual como más adelante se defenderá. Pues bien, se podría adoptar otra perspectiva a la hora de abordar esta cuestión, fijándose en la cobertura del seguro de responsabilidad civil, y así discernir hasta qué punto la contratación de dicho seguro pretende solamente resarcir al administrador de los gastos ocasionados por el desempeño de su cargo y protege el interés social, o solamente el interés del administrador protegiendo únicamente sus intereses personales. Teniendo en cuenta que el contrato de seguro no cubre los supuestos de actuación dolosa del asegurado y el principio de especialidad de los riesgos que rige en este clase de seguros, la virtualidad del seguro de responsabilidad civil se reduciría si así se establece en la póliza correspondiente a los supuestos en que la responsabilidad del administrador surge a consecuencia de una acción u omisión con culpa, aun leve. Igualmente, también podría cubrir los supuestos legales de responsabilidad objetiva. Solamente en este segundo caso se podría entender que el administrador podría sufrir perjuicios por el mero ejercicio de su cargo sin haber tenido una actuación, al menos culposa, que no propiamente gastos. Si se trata, en cambio, de una responsabilidad por daños ocasionados por una acción u omisión suya negligente, el hecho de que las consecuencias económicas derivadas de su declaración como responsable sean cubiertas por un seguro de responsabilidad civil pagado por la propia sociedad resulta inapropiado, y en todo caso debe considerarse como una retribución en especie que excede de la mera compensación de los gastos ocasionados por el desempeño de su cargo.

Precisamente en esta dirección debe subrayarse la inclusión expresa dentro del derecho de resarcimiento de gastos del administrador de los daños y perjuicios que pueda sufrir en el ejercicio de su cargo en virtud del art. 46.5. in fine LCCV. Se puede discutir si dentro del concepto de gastos, término utilizado normalmente en la regulación aplicable, se 
pueden considerar implícitamente incluidos o no también los daños y perjuicios que puede sufrir un administrador en el ejercicio de sus funciones. En cualquier caso, deberá ser un daño directo a sus intereses patrimoniales, ya que de lo contrario resultaría un exceso en la protección dispensada al administrador basada, sobre todo, en el carácter no retribuido que se presume en general legalmente para este cargo. Asimismo, deberá ser un daño directo, que no suponga, a su vez, un daño para la sociedad cooperativa. En caso contrario, se estaría "blindando" al administrador respecto de una eventual exigencia de responsabilidad en el ejercicio de su cargo, evitando así que tenga consecuencias relevantes una eventual actuación inadecuada por su parte. De forma similar a lo que puede ocurrir en caso de que la sociedad asuma el coste directa o indirectamente de un seguro de responsabilidad civil para el administrador.

En cualquier caso, este derecho de resarcimiento es en general un derecho de los administradores de una sociedad cooperativa que no podrán derogar ni los estatutos, ni la Asamblea General, salvo el art. 43.2. Ley 18/2002, de 5 julio, de Cooperativas de Cataluña (en adelante LCCat) que condiciona la existencia de este derecho a su previsión estatutaria.

Asimismo, no se suele establecer quién es el órgano competente para la fijación del importe de los gastos, ni siquiera si debe determinarse estatutariamente este extremo. Únicamente en la LCCat y en la LCCV se prevén excepciones, por un lado, en el art. 43.2. LCCat mencionado anteriormente se exige la fijación estatutaria tanto del propio derecho de los administradores, como del órgano encargado de fijar su cuantía, y, por otro lado, el art. 46.5. LCCV otorga la competencia para su fijación a la Asamblea general al igual que para una eventual retribución de los administradores. De todos modos, se puede considerar que el órgano encargado de hacerlo no será la Asamblea general, aplicando analógicamente lo que se prevé respecto a la retribución de los administradores (Gadea, Sacristán, Vargas, 2009:311), sino que será el propio órgano de administración, sin perjuicio de que el órgano de administración someta a la ratificación de la Asamblea general su acuerdo y de que los socios pueden tener acceso a la información sobre sus cuantías a través de las cuentas anuales que debe presentar el órgano de administración y que deben ser aprobadas por la propia Asamblea. Si bien es cierto que otorgar esta facultad al propio órgano de administración, resulta peligroso por el evidente conflicto de interés que concurre, también lo es que en todo caso deberán acreditarse los gastos en que haya incurrido el administrador para que pueda obtener la compensación por ellos (Gadea, 2000:184). Asimismo, si la información reflejada 
al respecto en las cuentas anuales no es veraz y completa, queda siempre la opción de exigir responsabilidad a los administradores (Gadea, Sacristán, Vargas, 2009:311). No obstante, como este tipo de medidas suelen resultar insuficientes debido a la falta de control del órgano de administración por parte de los socios en cooperativas de cierto tamaño y características, sería recomendable incrementar la transparencia sobre esta cuestión, y establecer, al menos, la obligación de incluir la partida anual que se ha destinado a este tipo de gastos en la memoria anual, así como un desglose de los conceptos que se han abonado por esta vía, por ejemplo desplazamientos, viajes, etc., al igual que se exige en muchos casos respecto a una eventual retribución que reciban los administradores.

Finalmente, debe subrayarse que no se establece ningún tipo de limitación legal, más allá de que los estatutos podrían establecer restricciones o límites, siempre que eso no suponga suprimir de facto este derecho de los administradores, salvo en la regulación catalana que sí lo permitiría al condicionar la existencia de este derecho de los administradores a su previsión estatutaria. De lege ferenda, deberían introducirse algunas limitaciones legales, consistentes en la precisión del concepto de gastos, así como en criterios para su fijación más allá de la exigencia de presentar los justificantes correspondientes, aunque se tratasen de restricciones supletorias, en defecto de previsión estatutaria al respecto, dado que ésta puede ser una vía de retribución indirecta y encubierta de los administradores que resulte opaca para los socios y para terceros acreedores.

\section{DERECHO LIMITADO A LA RETRIBUCIÓN POR EL EJERCICIO DEL CARGO}

\subsection{Regla general: presunción de gratuidad}

Se establece en general una presunción de gratuidad del cargo de administrador de la sociedad cooperativa. Esto es así claramente en la legislación autonómica vasca que permite que los cargos sean retribuidos si así se decide en los estatutos o, en su defecto, mediante acuerdo de la Asamblea general (art. 43. párr. $1^{\circ}$ LCE). Por tanto, puede decidir en un ejercicio determinado la Asamblea general retribuir a los administradores, más si se quiere que eso se repita anualmente y no dependa de una mayoría ordinaria de la voluntad social deberá incluirse estatutariamente tal previsión. La legislación estatal se muestra en un principio más restrictiva, ya que literalmente solamente se alude al eventual carácter retribuido del cargo de administrador si se trata de una persona que no es, a su vez, socio de la cooperativa (art. 40 LC) (Morilla, Feliú, 2000:274; García Mas, 2001:189; Olavarría, 2011:138). No obstante, si 
se tienen en cuenta los antecedentes legislativos, incluida la anterior Ley 3/1987, de 2 de abril, General de Cooperativas, que solamente se refería a que el administrador realizase tareas de gestión directa, y otros preceptos como el art. 21.2.b) LC que no distingue entre si los consejeros son socios o no al referirse a los asuntos competencia de la Asamblea general, debe concluirse que en realidad se permite que el cargo de administrador sea retribuido sea éste, a su vez, socio o no siempre que así se establezca. Esta exigencia solamente se pretendía establecer respecto de los interventores, pero la redacción vigente omite dos comas que aclaraban este matiz (Gadea, Sacristán,Vargas, 2009:304, Pastor, 2002:145; Paniagua, 2005:223; Paz Canalejo, 2002:140-146). Igualmente, de forma similar se prevé en otras regulaciones autonómicas.

Sin embargo, en algunas otras legislaciones autonómicas no se permite que los administradores sean retribuidos en determinados supuestos, o incluso se rompe con la presunción de gratuidad imponiéndose que sean retribuidos si se dan determinadas condiciones. Así sucede en virtud del art. 46.5. LCCV, art. 39.2. LCA, y del art. 38.6. LSCExt, que sólo permiten que sean retribuidos los miembros del Consejo Rector que realicen tareas de gestión directa, lo que parece una referencia a los administradores que sean, a su vez, altos directivos de la sociedad y/o que tengan facultades delegadas por parte del Consejo Rector. En un sentido similar, aunque de forma más amplia, en otras regulaciones se hace referencia a que realicen tareas encomendadas por la Asamblea general (art. 53 LCCan; art. $50 \mathrm{LCCyL}$ ). Este posicionamiento en cuanto al carácter retribuido o no del cargo se concreta aún más en algunas regulaciones autonómicas que hacen referencia concretamente al administrador único, a los administradores mancomunados o solidarios, al consejero delegado, al miembro de la comisión ejecutiva (art. 46.5. LCCV), y también a otra serie de cargos similares conforme al art. 49 LSCA. Esta distinción se puede encontrar también en la Jurisprudencia, así en la Sentencia del Tribunal Supremo de 11 de julio de 2007, e igualmente en la Sentencia de la Audiencia Provincial de Ciudad Real de 18 de abril de 2001 que aluden a las tareas de gestión directa que puede realizar un administrador y que le son encomendadas por la Asamblea general como, por ejemplo la negociación de préstamos, la realización de trámites administrativos, y otras tareas que si no realizase el administrador la sociedad cooperativa debería encargar su realización a terceras personas. En definitiva se estima que sólo este tipo de tareas merecen una retribución. Por su parte, se va más lejos en el art. 43.5. LCM que atribuye el derecho a obtener una remuneración a los consejeros independientes, mientras que los demás miembros del Consejo Rector recibirán una remuneración sólo si así 
se fija estatutariamente, por lo que parece considerar que los consejeros independientes tendrán un perfil más profesional y se encargarán de tareas que irán más allá de la mera asistencia a reuniones del Consejo Rector, interviniendo, por tanto, en la gestión diaria de la sociedad cooperativa.

Esta visión restrictiva de la posibilidad de que el cargo de administrador en una cooperativa sea retribuido parece encontrar su fundamento último en la falta propiamente de ánimo de lucro de la sociedad cooperativa, así como en el hecho de que el administrador si es, a su vez, socio, puede ver retribuida su actividad en la cooperativa de otras maneras. Eso sí, en las cooperativas de viviendas se prohíbe la percepción de remuneraciones o compensaciones del administrador por el desempeño del cargo (por ejemplo, art. 89.6.párr.2º LC) debido a los peculiares problemas que puede plantear esta clase de cooperativas y que no se analizarán en este trabajo. En cualquier caso, lo que no está justificado es esta disparidad legislativa. La atención del legislador no debería centrarse en si se permite o no y en qué casos la retribución de los administradores de una sociedad cooperativa, sino en su determinación y en sus límites, aspectos que como se comprobará más adelante se encuentran en general apenas desarrollados. Además, la cuestión de la retribución debería contemplarse de una forma global, esto es, la retribución de una persona que ostente el cargo de administrador o de los miembros del Consejo Rector en una cooperativa puede provenir no sólo de una remuneración por el desempeño de sus funciones como administrador, sino también en virtud de otras relaciones jurídicas con la cooperativa, que pueden ser, a su vez, ficticias o no.

\section{2. Órgano competente para la determinación de la remuneración}

Si se pretende que los administradores reciban una retribución por el ejercicio de sus funciones, una primera cuestión que se plantea es quien es el órgano competente para su fijación. Más concretamente si debe estar o no previsto estatutariamente el carácter retribuido del cargo de administrador, así como el sistema elegido y las bases que permitan su fijación anualmente. Desde luego resulta más adecuado que se determine estatutariamente si son o no retribuidos los cargos de administrador en la sociedad cooperativa (así en el art. 43.5. LCM; 46.5. LCCV; art. 49 LSCA; art. 60.1. LCCyM; art. 76 LPA; art. 58 LSCRM; art. 62 LCIB; art. 51 LCLR). En alguna regulación se permite, en defecto de previsión estatutaria, que lo decida la propia Asamblea general (art. 43 LCE; art. 47 LCG; art. 39.2. LCA; art. 38.6. LSCExt). En cambio, en otras se prevén como opciones alternativas su previsión estatutaria o 
su adopción por parte de la Asamblea general mediante la aprobación del correspondiente acuerdo social (art. 43.2. LCCat; art. 37.5. LCN en la medida en que esta última no hace referencia a la remuneración de los administradores dejando a los estatutos o a la Asamblea general la facultad de regular el funcionamiento interno del Consejo Rector), e incluso en otras legislaciones autonómicas sólo se alude a la Asamblea general teniendo en cuenta que solamente se permite la retribución a los administradores si llevan a cabo tareas de gestión encomendada por la propia Asamblea general a estos últimos (art. 50 LCCyL; art. 53 LCCan). Desde luego no parece conveniente que sea la Asamblea general la que decida en cada ocasión si debe o no retribuirse al administrador, cuya cuantía será la propuesta por los propios administradores.

Además, también debería establecerse en los estatutos el sistema retributivo a emplear, y las bases para fijar anualmente su cuantía por parte de la Asamblea General (así en el art. 46.5. CCV; art. 60.1. LCCyM; art. 76 LPA; art. 58 LSCRM; art. 62 LCIB; art. 51 LCLR). Cabe señalar como en el art. 43.5. LCM únicamente se hace referencia a la fijación de su importe bien estatutariamente, bien por parte de la Asamblea general, e incluso conforme al art. 49 LSCA el sistema de retribución y su cuantificación se deben acordar por la Asamblea general a instancia del órgano de administración. Por consiguiente, hay una excesiva divergencia entre las regulaciones existentes en cuanto a quien es el órgano competente y, sobre todo de qué modo se puede decidir si el cargo es retribuido, y lo que es más importante su importe. Debería exigirse una reserva estatutaria sobre el carácter retribuido del cargo, el sistema de retribución y las bases para su fijación anualmente por parte de la Asamblea General. Es más, el sistema y las bases debería incluir también la precisión de los conceptos retributivos que se van a incluir como puede ser una retribución fija, una variable en función de determinados indicadores, unos sistemas de ahorro o previsión, primas de seguros, o indemnizaciones por cese.

Una vez fijada la remuneración, resulta conveniente introducir medidas de transparencia y de publicidad, que no deben soslayar la conveniente previsión legal de limitaciones de carácter sustantivo como se analizará seguidamente. Este tipo de medidas se reducen a una sola en la legislación aplicable, como es la inclusión de la cuantía de la retribución de los administradores en la memoria anual (art. 40 LC; art. 60 LCCyM; art. 76 LCPA; art. 62 LCIB; art. 58 LSCRM; art. 51 LCLR), que ni siquiera se contempla en todas las regulaciones. Esta previsión legal es incompleta e insuficiente, ya que no se exige que se 
incluya también en dicha memoria anual el importe recibido por el administrador en concepto de gastos ocasionados por el desempeño de su cargo, y lo que ha podido recibir si, a su vez, mantiene una relación laboral o de otro tipo con la sociedad cooperativa. Se trata, en definitiva, de que se pueda conocer cuál es la cuantía total que ha recibido el administrador por la prestación de todo tipo de servicios y por medio de cualquier tipo de contrato o relación con la sociedad cooperativa. Es más, esta información también debería en su caso alcanzar a la retribución recibida de otras sociedades cooperativas que pueden estar en el mismo grupo cooperativo.

Este doble e incluso múltiple vínculo que puede tener el administrador con la sociedad cooperativa suele admitirse (Gadea, Sacristán, Vargas, 2009:307), a pesar de que en no pocas ocasiones resulta difícil deslindar las funciones propias del cargo de administrador de las de un contrato laboral de alta dirección o de las de un contrato de arrendamiento de servicios. Esto se refleja, por ejemplo en el insuficiente, aunque único, art. 45.2. LCCV que establece que el administrador cesado no tendrá derecho a ninguna compensación económica salvo la que se pueda derivar de las relaciones laborales o de arrendamiento de servicios que tenga con la sociedad cooperativa. Lo contrario supondría derogar el principio de libre revocabilidad del administrador. El problema surge cuando el administrador mantiene otro tipo de relaciones jurídicas con la cooperativa, que puedan dificultar de facto su libre revocabilidad.

\subsection{Limitaciones a la fijación de la remuneración}

Apenas hay limitaciones legales respecto al sistema de remuneración empleado y a su cuantía. Precisamente en este aspecto se vislumbra con más claridad la escasa atención y el carácter deficiente e incompleto de la regulación en este punto.

En cuanto al sistema de remuneración, solamente en algunas legislaciones autonómicas se hace referencia al sistema basado en los resultados del ejercicio económico de la sociedad cooperativa, esto es, fundamentalmente en una participación en los beneficios por parte del administrador. Es evidente el riesgo que conlleva la elección de este sistema, al menos si se utiliza como único criterio para fijar la retribución. De esta manera, el administrador puede estar más interesado en un beneficio a corto plazo que se debe producir en un ejercicio económico, que en la sostenibilidad de la sociedad cooperativa a medio y largo plazo y en el cumplimiento de los principios cooperativos. Por estas razones, no se permite fijar, en su caso, la retribución de los administradores conforme a este sistema en virtud del 
art. 50 LCCyL; art. 39.2. LCA; art. 38.6. LSCExt y art. 53 LCCan. Se defiende esta prohibición por parte de la doctrina (Gadea, 2000:184), que en la anterior Ley 3/1987, de 2 de abril, General de Cooperativas, sí se contenía (art. 59). Cabe señalar que en el ámbito de las sociedades de capital sí se permite, pero se establecen una serie de limitaciones, llegando incluso a una limitación porcentual en el caso de la sociedad de responsabilidad limitada [art. 218 Real Decreto Legislativo 1/2010, de 2 julio, por el que se aprueba el texto refundido de la Ley de Sociedades de Capital (en adelante LSC) recientemente modificado por la Ley 31/2014, de 3 de diciembre, por la que se modifica la Ley de Sociedades de Capital para la mejora del gobierno corporativo].

No se establece, por su parte, ninguna referencia sobre otros posibles sistemas que pueden conllevar el pago de una remuneración fija, o variable en función de otros indicadores distintos de los resultados económicos de la sociedad, o una combinación de ambos componentes. Igualmente, tampoco se alude a si la retribución puede ser en metálico, o en especie, como aportaciones sociales, o la transmisión de derechos que supongan la posibilidad de suscribir aportaciones voluntarias, obligatorias o de otro tipo de la sociedad cooperativa en un plazo y a un precio determinados, u otra serie de prestaciones no dinerarias, como puede ser la entrega o el uso de un vehículo, o aportaciones a un fondo o plan de pensiones.

Además, se podrían establecer sistemas diferentes para los administradores en función de su grado de compromiso y de su dedicación al cargo (Gadea, Sacristán, Vargas, 2009:307).

Más discutible resulta la posibilidad de incluir como remuneración una compensación en caso de cese (Gadea, Sacristán, Vargas, 2009:307), si tenemos en cuenta el principio de libre revocabilidad ya mencionado. Si así se hiciera, se estaría impidiendo de facto la revocación libre del administrador por parte de la Asamblea general, lo que no estaría justificado, más allá de que en la práctica se consiga un resultado análogo por medio de un contrato laboral de alta dirección o de otro tipo de vínculo con la sociedad. Igualmente, resulta difícil justificar que el administrador tenga derecho a una indemnización en caso de cese por haber incumplido sus funciones. En esta dirección, cabe destacar el recientemente modificado art. 217.2.f) LSC, que prevé que el administrador de una sociedad de capital no podrá percibir, en su caso, la indemnización pactada por cese si ha incumplido sus funciones. Esta norma es heredera, aun bastante laxa, del régimen de las entidades de crédito recogido en la Ley 10/2014, de 26 de junio, de ordenación, supervisión y solvencia de entidades de crédito, concretamente de sus arts. 32-36 que establecen un control mayor no sólo formal, sino 
especialmente sustantivo o material de la política de remuneraciones de los administradores y otros empleados que incidan significativamente en la asunción de riesgos de las entidades de crédito.

Respecto a la cuantía de la retribución, no se establecen apenas limitaciones. Solamente en algunas normativas autonómicas se prevén algunas restricciones. Así sucede en el art. 43.5. LCM que establece la necesidad de que se fijen las remuneraciones con criterios de moderación, termino éste que no deja de ser ambiguo y difícil de precisar, ya que dependerá de las circunstancias concurrentes en cada supuesto valorar si realmente la remuneración percibida por los administradores es moderada, en otras palabras, razonable o no. Este criterio de moderación se considera que debe regir con especial intensidad en las sociedades cooperativas por sus características desde un punto de vista de lógica económica (Gadea, Sacristán, Vargas, 2009:308). Más allá de esta consideración genérica que debe reforzarse, solamente en dos regulaciones se establecen limitaciones algo más concretas. Por una parte, se exige que las remuneraciones sean siempre proporcionadas a las prestaciones efectivamente realizadas en el ejercicio del cargo por parte del administrador (art. 43.5. LCM; art. 60.1. in fine LCCyM), posición más adecuada que prohibir sin más la retribución de los administradores que no realicen tareas de gestión directa, y que permite retribuir en mayor medida a quien realmente presta más servicios a la sociedad cooperativa, y contribuye, en definitiva, más a la gestión y al desarrollo de la cooperativa. Igualmente, las remuneraciones deben ser proporcionadas al volumen económico de la cooperativa (art. 43.5. LCM; art. 60.1. in fine LCCyM), en otras palabras, a los gastos en gestión que se pueda permitir la cooperativa dado su tamaño. Por otra parte, la remuneración podrá abonarse con cargo a excedentes disponibles, lo que no puede suponer de ninguna manera que no se puedan cubrir los Fondos obligatorios y estatutarios, ni la posibilidad de retornos a los socios (art. 43.5. LCM; art. 60.1. in fine LCCyM). De esta forma se intenta garantizar que la prioridad en ningún caso sea la remuneración de los administradores, sino la cobertura de los fondos obligatorios y estatutarios que pueda tener la cooperativa y proceder, en su caso, antes al reparto de los retornos cooperativos a los socios que a retribuir a los administradores.

Como se ha puesto de manifiesto a lo largo del presente epígrafe, el control sustantivo de la política retributiva es apenas inexistente. En cualquier caso, no se debe estimar imposible un control material de los sistemas, de los conceptos y de la cuantía de la remuneración de los administradores. Si bien es cierto que todavía queda por reforzar el que 
se puede denominar como control formal, esto es, las medidas de transparencia y publicidad de este aspecto del gobierno de las sociedades cooperativas que suele ser el objeto central de atención de la regulación (Gadea, Sacristán, Vargas, 2009:309).

\section{BREVE REFERENCIA A LA POSIBLE IMPUGNACION DE LOS ACUERDOS SOCIALES RELATIVOS A LA REMUNERACION DE LOS ADMINISTRADORES}

Dado que como se ha comprobado si se establece el carácter retribuido del cargo de administrador, no hay apenas limitaciones a su cuantía, y en no pocas ocasiones ni siquiera se exige la previsión estatutaria del sistema de remuneración y las bases para su fijación anual por parte de la Asamblea general, resulta conveniente plantearse la eventual eficacia de otros instrumentos de la legislación cooperativa. Esta falta de regulación "no significa una absoluta libertad en la política de remuneraciones" (Gadea, Sacristán, Vargas, 2009:308), sino que el interés social como límite general debe cumplir también esta función respecto a la política retributiva de los administradores de una sociedad cooperativa.

En este sentido, como será la Asamblea general el órgano social que fijará, en su caso, con mayor o menor libertad en función de si los estatutos prevén o deben prever el sistema y las bases para su posterior fijación de su cuantía al cierre del ejercicio social, debe abordarse la posible impugnación de los acuerdos de la Asamblea general cuyo contenido verse sobre la remuneración de los administradores.

Podrán ser impugnados los acuerdos de la Asamblea General que sean contrarios a la Ley, que se opongan a los Estatutos o lesionen, en beneficio de uno o varios socios o terceros, los intereses de la cooperativa (art. 31.1. LC; art. 39.1. LCE; art. 38 LCM; art. 38 LCCat; art. 40 LCCV; art. 40 LCG; art. 35 LSCA; art. 39 LCCyL; art. 36 LCA; art. 54 LCCyM; art. 57 LCPA; art. 42 LCCan; art. 46 LCIB; art. 35 LSCExt; art. 47 LSCRM; art. 44 LCLR; art. 36 LCN). En este sentido, dadas las escuetas normas legales sobre la retribución de los administradores, las causas de impugnación de este tipo de acuerdos sociales consistirán normalmente en que son contrarios a los estatutos, si éstos establecen algunas pautas, y no se cumplen sin haberse modificado previamente los estatutos sociales. Y sobre todo, se podrá fundar esta impugnación del acuerdo social correspondiente en que éste es contrario al interés de la sociedad cooperativa en beneficio de los administradores, ya sean éstos, a su vez, socios o no. El problema reside en determinar qué debe entenderse concretamente por interés social en una sociedad cooperativa, concepto que no está definido ni concretado legalmente. En el 
ámbito de las sociedades de capital, también se alude al interés social como un límite genérico, y se define únicamente como el interés de la sociedad, lo que ha suscitado principalmente dos posiciones en la doctrina debido a que en el seno de una sociedad se encuentran representados múltiples intereses, que no coinciden siempre. Se puede estimar que el interés social se correspondería con el interés de los socios (Duque, 1957: 73 y ss.; Alfaro, 1995: 51 y ss.), como sujetos del contrato social. Igualmente, se puede adoptar una visión más amplia, y considerar que el interés social no sólo está constituido por los intereses de los socios, sino también por los de otros sujetos contemplados y protegidos en la legislación aplicable, como, por ejemplo, los acreedores de la sociedad, sus trabajadores o la sociedad en general (Esteban, 1982: 123 y ss.; Alonso, 1991: 559-561). En concreto, ante una sociedad cooperativa se puede defender aún más esta segunda postura, conectando los intereses de la cooperativa con los principios cooperativos, que incluyen en séptimo lugar el relativo al interés por la comunidad en la que se insertan. No obstante, esta cuestión no puede ser más desarrollada en el marco de este trabajo.

En cualquier caso, un acuerdo social que fije una retribución excesiva teniendo en cuenta las circunstancias concurrentes como son, especialmente una situación económica delicada de la sociedad cooperativa, unos resultados económicos negativos, o una gestión inadecuada de los administradores, e incluso la amplia superación de la media de remuneración en el sector de que se trate, podrá llegar a ser considerado anulable y dejado consecuentemente sin efecto.

Igualmente, también se podrán impugnar los acuerdos que versen sobre el resarcimiento a los administradores de los gastos ocasionados por el desempeño de sus cargos. En este supuesto, puede tratarse de acuerdos de la Asamblea general, y también más habitualmente de la impugnación de acuerdos del Consejo Rector, cuyos acuerdos también pueden impugnarse aparte de por ser contrarios a la ley o a los estatutos, por ser contrarios a los intereses de la cooperativa en beneficio de uno o más socios o terceros (art. 37 LC; art. 49 LCE; art. 44 LCM; art. 47 LCCat; art. 46.6. LCCV; art. 52 LCG; art. 41 LSCA; art. 45 LCCyL; art. 68 LCCyM; art. 72 LCPA; art. 48 LCCan; art. 54 LCIB; art. 43 LSCExt; art. 53 LSCRM; art. 55 LCLR). No obstante, si el órgano de administración está compuesto por un administrador único, o administradores mancomunados o solidarios, y la Asamblea general no adopta ningún acuerdo social específico sobre este tema, solamente podrá valorarse este aspecto y su adecuación al interés de la sociedad cooperativa en el marco de la censura de la 
gestión social de los administradores y más concretamente de la aprobación de las cuentas anuales.

Además, hay que tener en cuenta los supuestos en que el cargo de administrador sea gratuito por no preverse nada en los estatutos o por previsión legal, y el administrador reciba retribuciones por parte de la sociedad cooperativa por la realización de trabajos o prestación de servicios distintos de los que derivan de su cargo. Si realmente estos servicios no se corresponden con los propios del cargo de administrador y son reales, podrán ser remunerados, y no habrá vulneración en este caso de una norma estatutaria. Así en la Sentencia de la Audiencia Provincial de Navarra (Sección 3 ${ }^{\mathrm{a}}$ ), de 2 de diciembre de 2002, $\mathrm{n}^{\mathrm{o}}$ 262/2002 (JUR 2003/32601) se desestimó la demanda de impugnación del acuerdo social de aprobación de las cuentas anuales, por considerar, entre otros motivos, que la retribución por trabajos concretos prestados por el administrador a la sociedad no vulneraba el interés social, ya que él los hizo en nombre e interés de la cooperativa. No se presta atención en la resolución judicial indicada a si los trabajos realizados por el administrador son inherentes o no a su cargo, aunque de la lectura de los fundamentos de derecho parece desprenderse que no lo eran. Y en cambio, sí se destaca que no resulta acreditado el perjuicio a la sociedad cooperativa, cuando debería bastar con que éste fuese potencial para poder considerar que el acuerdo social impugnado vulneró el interés social, y en consecuencia resultaba inválido.

\section{INCIDENCIA DEL CARÁCTER RETRIBUIDO DEL CARGO Y DE SU IMPORTE EN EL RÉGIMEN DE RESPONSABILIDAD DE LOS ADMINISTRADORES}

Los administradores deberán responder por los daños causados a la propia sociedad cooperativa, a los socios, y a terceros como los acreedores sociales. Los presupuestos para que concurra la responsabilidad de los administradores son una acción u omisión contraria a la ley, a los estatutos o a sus deberes, implicando cualquiera de estos supuestos una conducta, al menos negligente o culposa; un daño; y una relación de causalidad suficiente entre la actuación del administrador y el daño (Gadea, Sacristán, Vargas, 2009: 302-304). De forma similar se regula en el ámbito de las sociedades de capital (Sánchez Calero, 2007: 63 y ss.; Marín de la Bárcena, 2005: 171). En cambio, en algunas regulaciones autonómicas el segundo presupuesto se formula de forma distinta, puesto que se alude al dolo, al abuso de facultades y a la culpa o negligencia grave del administrador como en la LCM, LCCV, LCA, LCLR, LCN, así como en la LSCExt con términos similares que no siempre idénticos, que recuerdan al art. 144 Código de Comercio que regula la responsabilidad de los socios colectivos y, por ende, 
en principio, también gestores en las sociedades colectivas. Por su parte, el art. 43 LC se limita a remitirse a la regulación aplicable a las sociedades anónimas, lo que supone actualmente su remisión a los arts. 236-241 LSC, de forma similar también en el art. 61 LSCRM. En cambio, otras normativas optan por regular con detalle el régimen de responsabilidad de forma similar (arts. 47-48 LCE; arts. 50-51 LSCA; arts. 45-46 LCCat; art. 47 LCCV; arts. 50-51 LCG; art. 51 LCCyL; art. 42 LCA; arts. 63-64 LCCyM; arts. 66-68 LCPA; art. 54 LCCan; arts. 63-64 LCIB; art. 42 LSCExt; art. 54 LCLR y más escuetamente en el art. $44 \mathrm{LCN}$ ), aunque omitiendo aspectos relevantes como, especialmente la acción individual de responsabilidad.

En definitiva, queda claro que la responsabilidad del administrador no es objetiva, y su conducta debe ser dolosa o culposa. No obstante, como ya se ha expuesto, no todos los administradores de una sociedad cooperativa perciben una remuneración. Es más, histórica y tradicionalmente se trata de cargos gratuitos, lo que genera no pocas tensiones y conflictos (Gadea, Sacristán, Vargas, 2009: 302). Por este motivo, se puede llegar a considerar que su responsabilidad en caso de que lleven a cabo una conducta negligente y a consecuencia de ella se produzca unos daños y perjuicios para la sociedad o para terceros debería minorarse teniendo en cuenta su eventual carácter no retribuido. En cambio, si su labor es retribuida estaría justificado exigirles con mayor rigor responsabilidad por los daños que puedan causar a la cooperativa o a terceros. En definitiva, se pretende así establecer un patrón de diligencia o un estándar de conducta distintos del administrador en función de si percibe o no una retribución por el ejercicio de su cargo. Este planteamiento solamente ha encontrado refrendo legal explícito en el art. 47.1. LCE, que afirma que la responsabilidad de los administradores “... deberá estimarse con más o menos rigor en función del carácter retribuido o no del cargo".

Esta diferenciación en función del carácter retribuido o no del cargo parece olvidar varios aspectos de importancia. En primer lugar, con independencia de la posibilidad de percibir una retribución por las labores realizadas, la asunción de un cargo como es la de administrador de una sociedad cooperativa debe realizarse responsablemente, y no puede ser su carácter no retribuido un argumento válido para minorar la responsabilidad del administrador, y, en definitiva, para estimar que éste debe cumplir con los deberes de diligencia y lealtad en menor medida por no percibir propiamente una remuneración por el ejercicio del cargo. Si bien es cierto que si se trata de un socio de la cooperativa, tiene la 
obligación de aceptar su designación como administrador, también lo es que uno de los principios cooperativos es el de puertas abiertas, por lo que si el socio no está dispuesto a asumir este tipo de cargos puede irse de la cooperativa. En segundo lugar, considerar que simplemente por el hecho de que el cargo no sea retribuido, el administrador no percibe ningún tipo de beneficio por el ejercicio de sus funciones no es en muchas ocasiones real. En efecto, puede emplearse la posibilidad de compensar gastos y perjuicios que ocasiona el ejercicio del cargo con el fin de retribuir indirectamente al administrador, o la de establecer otro tipo de relaciones entre el administrador y la sociedad que permitan que el primero obtenga una remuneración por prestar otro tipo de servicios o por ejercer labores en ocasiones difícilmente distinguibles de las que lleva a cabo como administrador. En último lugar, esta medida no es desde luego una manera de incentivar la diligencia y la profesionalidad en la labor de administración de una sociedad cooperativa, puesto que un adecuado régimen de responsabilidad de los administradores puede tener un considerable efecto disuasorio y preventivo en cuanto a la realización de conductas inadecuadas para los intereses de la sociedad cooperativa. Por todos estos motivos, no se debería tomar en consideración el carácter retribuido o no del cargo de administrador a la hora de determinar su responsabilidad y el rigor de ésta.

De todos modos, el administrador cuenta con unas causas de exoneración que suponen, en general, no haber intervenido en la adopción y ejecución del acuerdo que ocasionó el daño, desconocer su existencia o conociéndolo hacer todo lo posible para evitar el daño (por ejemplo, art. 37 LC; art. 47.2. LCE). No obstante, se encuentran posiciones diferentes en la legislación aplicable en cuanto a si la ausencia por parte de un miembro del Consejo Rector en la reunión, esto es, el desconocimiento del acuerdo le exonera de responsabilidad o no, y consecuentemente es necesario que el administrador haya hecho algo más, haya adoptado realmente una actitud activa, que resulte acorde con su deber de diligencia, para poder exonerarse de responsabilidad. Así en el art. 50.3.b) LSCA y en el art. 51.2.b) LCCyL se alude a la ausencia de un miembro del Consejo Rector como causa de exoneración, pero matizándolo con el principio de la buena fe al exigir que no hayan tenido oportunidad de conocer el acuerdo adoptado. A pesar de este matiz, no deja de ser criticable, que se llegue a considerar que el administrador puede no tener oportunidad de conocerlo, cuando debería derivarse su obligación de conocimiento del acuerdo de su deber de diligencia. 
Se puede reclamar la responsabilidad de los administradores por los daños causados directamente al patrimonio o intereses de la sociedad cooperativa mediante el ejercicio de la acción social. Sin embargo, la denominada acción individual solamente se regula en algunas normativas autonómicas (art. 48.6. LCE; art. 51.6 LSCA; art. 47 LCCV; art. 46.3. LCCat; art. 42.3. LCA; art. 68 LCPA; art. 54.3. LCCan; art. 64.5. LCIB; art. 54.7. LCLR). Cabe recordar que la legislación estatal se remite a la legislación aplicable a las sociedades de capital, que sí prevé expresamente la acción individual de responsabilidad frente a los administradores (art. 241 LSC). Mediante la acción individual un tercero como un socio o un acreedor puede reclamar a los administradores de la cooperativa, si estos últimos le han causado un daño directamente en sus intereses patrimoniales. Conviene subrayar que en algunas normativas autonómicas únicamente se alude a la posibilidad de que el tercero que exija responsabilidad a los administradores sea un socio (art. 51.6 LSCA; art. 47.4. LCCV; art. 64.5. LCIB), obviando, por ejemplo el supuesto de un acreedor social no socio.

No puede obviarse, por último, que una remuneración que pueda considerarse excesiva, en especial a la luz de las circunstancias concurrentes, como una situación preconcursal de la sociedad cooperativa, puede constituir motivo suficiente para reclamar la responsabilidad de los administradores por los daños y perjuicios ocasionados a la sociedad cooperativa. Si concurre una causa de disolución, e incluso debe solicitarse la declaración de concurso, se contempla generalmente el deber del administrador de promover la disolución de la sociedad cooperativa, y solamente en algunas se establece una responsabilidad específica de los administradores por no promoverla (art. 97.4. LSCRM; art. 112.5. LCCyM; art. 95.5. LCM; art. 92.4. LCCan). Aunque no haya en general una norma especial como la del art. 367 LSC en la legislación cooperativa, se podrá exigir responsabilidad a los administradores en caso de que no hayan promovido la disolución y/o el concurso de la sociedad cuando era debido, acreditando que se ha producido un daño en los intereses de la sociedad o de un tercero como puede ser un acreedor social por el incumplimiento de una obligación legal por parte de los administradores (Sacristán, 2006: 139-166). No obstante, hay que tener en cuenta, en caso de que la cooperativa sea declarada en concurso de acreedores, la existencia de una responsabilidad concursal si el concurso se califica como culpable y que puede afectar a los administradores sociales pudiendo llegar a responder éstos personalmente por las deudas sociales. 
Desde luego ni este último ni otros serán supuestos sencillos, dado que puede resultar difícil acreditar alguno de los presupuestos de la acción de responsabilidad, como el daño o perjuicio sufrido por la sociedad cooperativa o por un tercero y la relación de causalidad entre el daño y la percepción de una excesiva retribución por parte de los administradores. Este aspecto se destaca en la Jurisprudencia, así en las Sentencias del Tribunal Supremo de 29 de septiembre de 2006, no 912/2006 (RJ 2006/6499), o de 11 de julio de 2007, no 809/2007 (RJ 2007/3883).

\section{CONCLUSIONES}

En general, se presume legalmente que el cargo de administrador en una sociedad cooperativa es gratuito, lo que no impide que el administrador tenga derecho a que se le resarzan los gastos ocasionados por el desempeño de su cargo. Este derecho apenas está regulado legalmente, y tampoco se exige que sea objeto de desarrollo estatutario, lo que puede suponer que se aproveche este derecho para encubrir una verdadera retribución a los administradores de las sociedades cooperativas. Asimismo, el propio concepto de gastos dista de ser claro y preciso, planteándose dudas con compensaciones que pueden considerarse fácilmente como retribuciones en especie como las dietas por asistencia a las reuniones del Consejo Rector, o las primas del seguro de responsabilidad civil de los administradores. Este último concepto lleva a plantearse si también los perjuicios que pueda sufrir el administrador en el ejercicio de su cargo se pueden entender incluidos en el concepto de gastos.

Si el cargo de administrador es retribuido, debería determinarse en cualquier caso el sistema, los conceptos retributivos, así como las bases para su fijación estatutariamente, aprobando anualmente la Asamblea general su importe concreto. Además, deberían establecerse restricciones, al menos estatutarias sobre el sistema de remuneración y su cuantía. Un sistema retributivo basado solamente en la participación en beneficios sin ulteriores limitaciones o que incluya una elevada indemnización por cese, o una retribución variable importante en función de indicadores cortoplacistas puede perjudicar notablemente la debida alineación de intereses entre el administrador y la sociedad cooperativa. En estos supuestos, el administrador tendrá un interés personal en conseguir los mejores resultados económicos en cada ejercicio social, sin que tenga el mismo aliciente por lograr la sostenibilidad de la sociedad cooperativa y su desarrollo a medio y largo plazo. Este riesgo no se soslaya por el mero hecho de que el administrador sea, a su vez, socio. 
Además, debería hacerse hincapié en la necesidad de reforzar la transparencia y la publicidad sobre la retribución del administrador, que debe comprender todos los ingresos que pueda obtener el administrador de la sociedad cooperativa con independencia de la vía empleada. En este sentido, no se debería permitir un doble vínculo del administrador con la sociedad, uno de carácter mercantil u orgánico, y otro laboral de alta dirección, sin que realmente se estén desarrollando por parte del administrador tareas diferentes y particulares. De lo contrario, se está dificultando en gran medida de facto el principio de libre revocabilidad de los administradores por parte de la Asamblea general, que supone la principal medida de control de la gestión social.

Como la regulación aplicable a las sociedades cooperativas es parca e insuficiente en este aspecto, solamente queda en caso de que la retribución del administrador sea excesiva atendiendo a las circunstancias la impugnación del acuerdo social correspondiente de la Asamblea general alegando principalmente la lesión de los intereses de la cooperativa en beneficio de un tercero o de un socio como puede ser el propio administrador.

Igualmente, cabe exigir responsabilidad a los administradores en caso de que concurran los presupuestos necesarios. Fundamentalmente deberá acreditarse la existencia de un daño, y su relación de causalidad con la conducta del administrador, concretamente con la percepción de una retribución excesiva y desproporcionada.

Asimismo, el carácter retribuido o no del cargo no debe afectar al patrón de diligencia de un administrador de una sociedad mercantil como es una cooperativa y en consecuencia al rigor con el que se debe exigir responsabilidad por los daños que ocasione a la sociedad o a terceros.

Finalmente, la responsabilidad de los administradores por no promover la disolución o, en su caso, el concurso de acreedores de la sociedad cooperativa debería regularse expresamente en la legislación sobre cooperativas, teniendo en cuenta en este último caso la eventual existencia de una responsabilidad concursal de los administradores si la sociedad es declarada en concurso y éste se califica como culpable.

\section{BIBLIOGRAFÍA}

ALFARO AGUILA-REAL, J. (1995) Interés social y Derecho de suscripción preferente. Madrid: Civitas. 
ALONSO LEDESMA, C. (1991) Algunas consideraciones sobre el juego de la cláusula del interés social en la supresión o limitación del derecho de suscripción preferente. En: Derecho mercantil de la Comunidad Económica Europea. Estudios en homenaje a José Girón Tena. Madrid: Civitas, pp. 559 y ss.

DUQUE, J. (1957) Tutela de la minoría. Impugnación de acuerdos lesivos (art. 67 LSA). Valladolid: Consejo Superior de Investigaciones Científicas.

ESTEBAN VELASCO, G. (1982) El poder de decisión en las sociedades anónimas. Madrid: Civitas.

GADEA SOLER, E.; SACRISTÁN BERGIA, F. y VARGAS VASSEROT, C. (2009) Régimen jurídico de la sociedad cooperativa del Siglo XXI. Realidad actual y propuestas de reforma. Madrid: Dykinson.

GADEA SOLER, E. (2000) Derecho de las Cooperativas (Análisis de la Ley 4/1993, de 24 de junio, de Cooperativas del País Vasco). $2^{\text {a }}$ edición. Bilbao: Universidad de Deusto.

GARCÍA MÁS, F. J. (2001) De los órganos de la sociedad cooperativa. En GARCÍA SÁNCHEZ, J. A. Cooperativas: comentarios a la Ley 27/1999, de 16 de julio. Vol. I. Madrid, pp. 139 y ss.

IRIBARREN BLANCO, M. (2005) El seguro de responsabilidad civil de los administradores y altos directivos de sociedades de capital $(D \& O)$. Madrid: Civitas.

MARIN DE LA BARCENA, F. (2005) La acción individual de responsabilidad frente a los administradores de sociedades de capital (art. 135 LSA). Madrid: Marcial Pons.

MORILLAS JARILLO, M.J. y FELIÚ REY, M. (2000) Curso de cooperativas. Madrid: Tecnos.

MUÑOZ MEDRAÑO, Ma C. y BRIONES PEÑALVER, J. (2011) Good governance in the entities of the social economy. CIRIEC-España, Revista de Economía Pública, Social y Cooperativa, $\mathrm{N}^{\mathrm{o}}$. 73, octubre, pp. 171-191.

OLAVARRIA IGLESIA, J. (2011) Órganos sociales II. El consejo rector y los administradores. En: FAJARDO GARCÍA, G. Cooperativas: Régimen Jurídico y Fiscal. Valencia: Tirant lo Blanch, pp. 129-142.

PANIAGUA ZURERA, M. (1997) La sociedad cooperativa. Las sociedades mutuas de seguros y las mutualidades de previsión social. Vol.1. T. XXII. En: JIMENEZ SANCHEZ, G. J. Tratado de Derecho mercantil. Madrid: Marcial Pons.

PASTOR SEMPERE, C. (2006) Órgano de administración. En: PULGAR EZQUERRA, J.; VARGAS VASSEROT, C. Cooperativas Agrarias y Sociedades Agrarias de Transformación. Madrid: Dykinson, pp. 493-563. 
PASTOR SEMPERE, C. (2002) Los recursos propios en las sociedades cooperativas. Madrid: Edersa.

PAZ CANALEJO, N. (2002) La sociedad cooperativa ante el reto de los mercados actuales. Un análisis no sólo jurídico. Madrid: Ministerio de Trabajo y Asuntos Sociales.

RONCERO SÁNCHEZ, A. (2002) El seguro de responsabilidad civil de los administradores de una sociedad anónima. Pamplona: Aranzadi.

SACRISTÁN BERGIA, F. (2006) El riesgo de responsabilidad del órgano de administración de las cooperativas en situaciones de insolvencia, o de pérdidas patrimoniales. REVESCO, Revista de estudios cooperativos, Segundo Cuatrimestre, №. 89, pp. 139-166.

SÁNCHEZ CALERO, F. (2007) Los administradores en las sociedades de capital. $2^{\mathrm{a}}$ edición. Madrid: Civitas.

VICENT CHULIÁ, F. (1990) Ley General de Cooperativas. T. XX. Vol. II. En: SANCHEZ CAlero, F. y AlBAladejo GARCiA, M. Comentarios al Código de Comercio y Legislación mercantil especial. Madrid: Edersa. 